\title{
Enhanced Cellulose Degradation of Wheat Straw during Aqueous Ethanol Organosolv Treatment
}

\author{
Martin Lindemann, ${ }^{\mathrm{a}, \mathrm{b}, *}$ Anton Friedl, ${ }^{\mathrm{a}}$ and Ewald Srebotnik ${ }^{\mathrm{a}}$ \\ The degradation of cellulose in wheat straw during aqueous ethanol \\ organosolv (AEO) treatment under different pulping conditions was \\ investigated. For this purpose, molecular weight distribution (MWD) and \\ degree of polymerization (DP) of the resulting cellulose pulp were \\ determined using high performance size exclusion chromatography \\ (HPSEC). The most pronounced effects regarding cellulose degradation \\ were observed when varying the ethanol-to-water ratio. UV detection in \\ HPSEC indicated that residual lignin in wheat straw fibers from organosolv \\ treatments does not occur in free form, but rather is associated with \\ hemicellulose (xylan) and to a minor extent also with cellulose. The \\ established method was suitable for relative comparisons of MWD of \\ variously treated wheat straw fibers and hence for obtaining information \\ regarding the severity of organosolv treatment in terms of cellulose \\ degradation. In summary, AEO treatment at a low ethanol-to-water ratio \\ favours the efficient delignification and removal of xylan from wheat straw, \\ but this occurs at the price of a greatly reduced fiber quality in terms of DP.
}

Keywords: Wheat straw; Liquid hot water treatment; Organosolv; High performance size exclusion chromatography; N,N-Dimethylacetamide / lithium chloride; Cellulose

Contact information: a: Institute of Chemical and Biological Engineering, Technische Universität Wien, 1060, Vienna, Austria; b: Competence Centre of Wood Composites and Wood Chemistry, Linz, Austria;

*Corresponding author: martin.lindemann@ @uwien.ac.at

\section{INTRODUCTION}

Wheat straw is an agricultural residue that occurs in large quantities and can be transported in a relatively dense, pressed form. Due to its typical low water content, it is easy to store and currently is only used for low value applications such as mulch (Bilalis et al. 2003), energy, and animal bedding (Ward et al. 2000). However, it may also be used in a lignocellulosic feedstock biorefinery, either without pretreatment to produce syngas via pyrolysis (Kamm and Kamm 2004) or by fractionation into its main components of cellulose, hemicellulose, and lignin. These cell wall components occur in tight association with each other, requiring harsh pulping conditions to separate them (Kamm et al. 2006). The recalcitrance of the lignocellulosic network mainly results from hydrogen bonds between cellulose, hemicellulose, and lignin, but also from chemical bonds between lignin and hemicellulose (Chen 2014). Furthermore, there is some evidence indicating that chemical bonds may also exist between cellulose and lignin (Lawoko 2005; Du et al. 2013).

For the selective fractionation of lignocellulose, different treatments are available depending on the subsequent valorization steps of the individual streams. Many pretreatments conducted with wheat straw involve pressurized water treatments from 160 ${ }^{\circ} \mathrm{C}$ to $240{ }^{\circ} \mathrm{C}$, carried out at neutral (liquid hot water, LHW) (Nabarlatz et al. 2007), acidic (Kabel et al. 2007), or alkaline (Saha and Cotta 2006) conditions, as well as steam explosions (Montane et al. 1998) and ethanol organosolv treatments (Wildschut et al. 
2013). LHW treatment is a very simple and cheap pretreatment technology using only water as a solvent at elevated temperatures and pressures, with the focus of solubilizing carbohydrates, mainly hemicelluloses (Kim et al. 2009). For organosolv treatment, typically an organic solvent or a mixture with water is used to dissolve mainly lignin and hemicelluloses at temperatures between $180^{\circ} \mathrm{C}$ to $220^{\circ} \mathrm{C}$. Cellulose is recovered as a solid fraction (Young and Akhtar 1998; Zhao et al. 2017) and may be sold as fibers or processed further to platform chemicals.

A combination of LHW and aqueous ethanol organosolv (AEO) treatment of wheat straw has been reported by few authors. Ruiz et al. (2011) reported a good xylose recovery and production of cellulose-enriched solids. Huijgen et al. (2012) found improved enzymatic glucose yields, but at a reduced lignin yield, due to the formation of "pseudo lignin" and recondensation during prehydrolysis. Preliminary studies in the authors' laboratory focused on optimization of treatment conditions during LHW and AEO treatment of wheat straw (Weinwurm et al. 2012). During LHW treatment at medium temperatures, hemicellulose- and cellulose-derived sugars were maximized. In contrast, during AEO treatment, a 1.5 to 5 fold lower amount of sugars was removed, less degradation of products occurred, and higher delignification was reached. However, the quality of the remaining cellulose fibers in terms of degree of polymerization (DP), as well as impurities such as residual lignin, hemicelluloses, and degradation products have not been determined. The DP is an essential indicator of fiber quality and can be calculated from molecular weight distributions obtained by high performance size exclusion chromatography (HPSEC) (Klemm et al. 1998; Henniges et al. 2014).

A common system for relative comparisons of cellulose molecular weight distributions by HPSEC is a refractive index (RI) detection and calibration with pullulan (Striegel 1997; Sjöholm et al. 2000). The HPSEC method requires complete dissolution of cellulose. Several aqueous, non-aqueous, derivatizing, and non-derivatizing solvents have been reported (Heinze and Koschella 2005; Liebert 2010). N,N-Dimethylacetamide $(\mathrm{DMAc}) / \mathrm{LiCl}$ is a viable non-derivatizing solvent suitable for various analytical techniques including ${ }^{13}$ C-NMR spectroscopy (Nehls et al. 1995), electrospray mass spectroscopy (Striegel 1997), and HPSEC (Silva and Laver 1997; Klemm et al. 1998). However, Potthast et al. (2002) reported severe degradation of cellulosic samples during dissolution when exceeding $85{ }^{\circ} \mathrm{C}$; thus, dissolution temperatures are a critical parameter when using $\mathrm{DMAc} / \mathrm{LiCl}$.

The aim of the present work was to monitor cellulose degradation and chemical composition of wheat straws after a combination of LHW treatment, followed by AEO treatment under varied pulping conditions. After the successful adaption of the cellulose dissolution method, the measurements of DP and MWD provided useful information about treatment severity and the quality of the cellulose-enriched fiber residue.

\section{EXPERIMENTAL}

\section{Materials}

Wheat straw specimens were harvested near Dürnkrut in lower Austria (two different batches) and stored in sealed bags. Straw lignin was obtained by precipitation during the AEO process (Weinwurm et al. 2016). Sulfuric acid ( $96 \%$ p.a.), ethanol ( $\geq 96 \%$, denatured with $1 \%$ MEK), and acetone ( $\geq 99,8 \%$ p.a.) were obtained from Carl Roth (Karlsruhe, Germany). N,N-Dimethylacetamide (DMAc, $\geq 99,9 \%$ for HPLC), LiCl

Lindemann et al. (2017). "Organosolv \& degradation," BioResources 12(4), 9407-9419. 9408 
anhydrous $(\geq 99 \%$, Redi-DriTM $)$, xylan from beechwood $(\geq 90 \%)$, analytical grade D-(+)glucose, D-(+)-xylose, D-(-)-arabinose, D-(+)-galactose, D-(+)-mannose, and L-(-)-fucose were from Sigma Aldrich (St. Louis, USA). $\mathrm{NaOH}(46 / 51 \%$ solution, HPLC electrochemical grade), and sodium acetate trihydrate (HPLC grade) used for HPAECPAD were from Fisher Scientific (Hampton, USA). Milli-Q-Water was prepared according to DIN ISO 3696 (1991). Milli-Q water, $\mathrm{NaOH}$, and sodium acetate eluents for HPAECPAD were filtered through a $0.2 \mu \mathrm{m}$ Nylon 66 membrane (Supelco, St. Louis, MO, USA), degassed, and stored under helium. The HPSEC eluent was prepared by dissolving $0.9 \%$ $\mathrm{LiCl}$ in DMAc, filtration through a $1.5 \mu \mathrm{m}$ PTFE membrane (Supelco), and was stored under nitrogen.

\section{Methods}

\section{Preparation of $L H W$ - and AEO-treated wheat straw}

The LHW- and AEO-treated wheat straws were prepared and provided by Denner and Weinwurm (Denner 2016; Weinwurm et al. 2016). Briefly, for the LHW treatment a $1 \mathrm{~L}$ high pressure autoclave (HDA 9/16, Zirbus, Germany) was filled with wheat straw (particle size 1 to $5 \mathrm{~mm}$ ) and demineralized water (1:11 weight ratio), heated to $180{ }^{\circ} \mathrm{C}$ in $60 \mathrm{~min}$, and then cooled. After multiple washing steps with water, the LHW treated straw was dried at room temperature and then transferred to five small $(45 \mathrm{~mL}) \mathrm{T} 316$ stainless steel reactors (Parr Instrument Company, Moline, IL, USA) for AEO treatment. Except for the optimization of dissolution in $\mathrm{DMac} / \mathrm{LiCl}$, which was done at $160{ }^{\circ} \mathrm{C}$ and $60 \mathrm{wt} . \%$ ethanol, AEO treatment conditions were $30 \mathrm{~min}$ at $200{ }^{\circ} \mathrm{C}$ and various ethanol-to-water ratios for all experiments. These conditions were chosen based on a preliminary set of experiments showing that varying the ethanol-to-water ratio at $200{ }^{\circ} \mathrm{C}$ had the most pronounced effects on cellulose degradation. The experiments were repeated under identical conditions with a different batch of wheat straw to check for reproducibility. Other parameters such as particle size and acetic acid had only minor effects on cellulose degradation, and the results are described elsewhere (Lindemann 2016). The obtained fibers were then processed according to the scheme presented in Fig. 1 to determine their chemical composition and molecular weight distributions. All measurements were performed in duplicate.

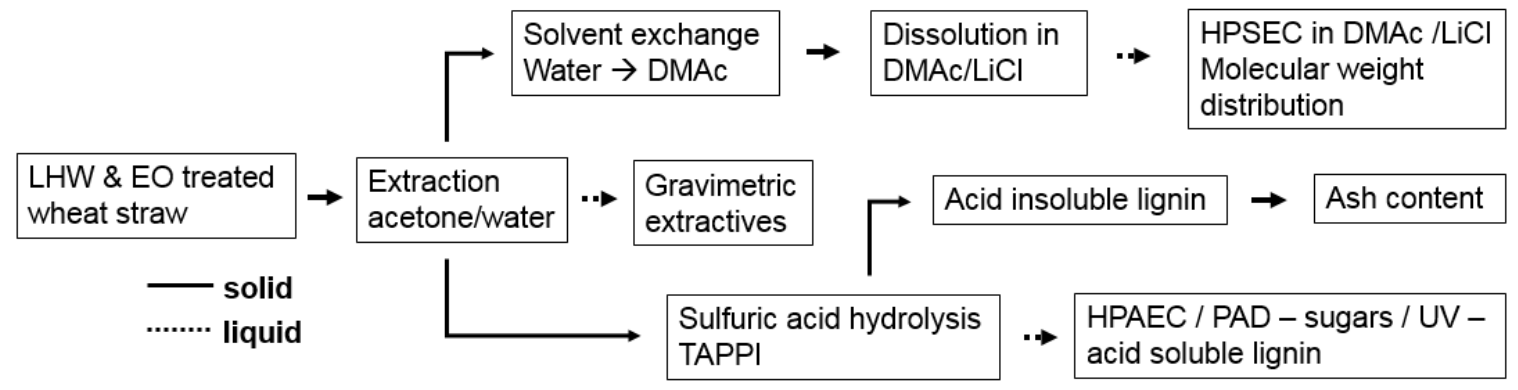

Fig. 1. Scheme for determination of chemical composition and molecular weight distributions of LHW and AEO treated wheat straw

\section{Removal of extractives}

Before determining chemical composition and molecular weight distributions, all lipophilic extractives were removed by pressurized solvent extraction (Speed Extractor E916, Büchi, Flawil, Switzerland). Fiber samples were freeze-dried (Christ Alpha 1-4 LD plus) before and after extraction and extraction was performed according to TAPPI T204 
cm-07 (2007) with slight modifications employing 4 consecutive cycles (10 min each) of acetone/water $(95 / 5 \mathrm{vol} \%)$ at $110{ }^{\circ} \mathrm{C}$ and $110 \mathrm{bar}$.

\section{Acid insoluble lignin, acid soluble lignin, and ash content}

A 2-step sequential sulfuric acid hydrolysis with $10 \mathrm{M} \mathrm{H}_{2} \mathrm{SO}_{4}$ at $23{ }^{\circ} \mathrm{C}$, followed by 3 wt. $\% \mathrm{H}_{2} \mathrm{SO}_{4}$ at $100{ }^{\circ} \mathrm{C}$ was carried out to convert polysaccharides from the lignocellulosic matrix into soluble sugars and separate it from acid-insoluble lignin. Details are given in the TAPPI T 222 om-98 standard (1998) for determining acid-insoluble lignin. The method was slightly modified in that smaller samples $(0.2$ to $0.5 \mathrm{~g}$ of sample per determination) were used with the amount of sulfuric acid adjusted accordingly. Acid soluble lignin and ash content were analyzed according to TAPPI UM 250 (1991) and TAPPI T211 om-02 (2002). Acid insoluble and acid soluble lignin are added up and referred to as lignin in the results.

\section{Carbohydrate analysis}

The carbohydrate composition of fibers was determined by quantification of monosaccharides in the sulfuric acid hydrolysate by high performance anion exchange chromatography with pulsed amperometric detection (HPAEC-PAD) on a Dionex ICS 5000 system (Thermo Scientific) using Dionex CarboPac PA1 guard and analytical (2 x $250 \mathrm{~mm}$ ) columns (Thermo Scientific). The column was preconditioned at $0.26 \mathrm{~mL} / \mathrm{min}$ in $200 \mathrm{mM} \mathrm{NaOH} / 65 \mathrm{mM}$ sodium acetate for $10 \mathrm{~min}$., followed by water for $7 \mathrm{~min}$. Samples of $10 \mu \mathrm{L}$ were then injected, and the monosaccharides were separated by isocratic elution in water using a post-column addition of $67 \mathrm{mM} \mathrm{NaOH}$ for $18 \mathrm{~min}$. No neutralization of the hydrolysate was carried out before injection, but the solutions of authentic sugar standards used for calibration were adjusted to the same $\mathrm{H}_{2} \mathrm{SO}_{4}$ concentration, as sulfate ions act as "pusher anions", resulting in a decrease in retention times (Davis 1998). To compensate sugar degradation during acid hydrolysis, recovery standards of the according monosaccharides were exposed to the same hydrolysis conditions as the samples except for the $10 \mathrm{M} \mathrm{H}_{2} \mathrm{SO}_{4}$ step as Davis (1998) reported that degradation losses during this step were negligible.

\section{Non-derivatizing dissolution of cellulose and HPSEC analysis}

For the determination of molecular weight distribution and degree of polymerization, LHW- and AEO-treated wheat straw was dissolved in the non-derivatizing cellulose solvent system DMAc/LiCl (Dawsey and McCormick 1990) and analyzed by HPSEC. The method was adapted for dissolving wheat straw cellulose obtained under the LHW and AEO treatment conditions used here. Temperature and time were optimized to achieve maximum dissolution without significant cellulose degradation. For solvent exchange (Ishii et al. 2008; Henniges et al. 2014), $50 \mathrm{mg}$ of each extracted wheat straw sample was swollen in $200 \mathrm{~mL} \mathrm{H}_{2} \mathrm{O}$, followed by mixing twice for $10 \mathrm{~s}$ in a Waring blender for disintegration of the fiber bundles. This resulted in better accessibility for the solvent. The fibers were filtered with a crucible $(10 \mu \mathrm{m}$ to $16 \mu \mathrm{m})$, vacuumed dry, washed twice with ethanol, and vacuumed dry again. Dried fibers were transferred to a $25 \mathrm{~mL}$ screwcap vial. A total of $10 \mathrm{~mL}$ of DMAc was added, and the mixture was shaken ( 120 RPM) overnight, filtered with a crucible $(10 \mu \mathrm{m}$ to $16 \mu \mathrm{m})$, vacuumed dry, and washed 3 times with DMAc. These activated wheat straw fibers were then mixed with $10 \mathrm{~mL}$ of $\mathrm{DMAc} / \mathrm{LiCl}(9 \%)$ and stirred for $72 \mathrm{~h}$ in a climate chamber at $32{ }^{\circ} \mathrm{C}$ to dissolve the cellulose. After centrifugation at $7.600 \times \mathrm{g}$ and $4{ }^{\circ} \mathrm{C}$ (Sorvall RC6 plus, Thermo Scientific), 
the dissolved cellulose was decanted, and the non-dissolved fiber residue was vortexed with fresh DMAc and centrifuged again. The supernatant was discarded, and the solid residue was washed with water, filtered over a tared nylon filter (Nylon $660.2 \mu \mathrm{m}$, Supelco), thoroughly washed again with water, dried in a desiccator, and gravimetrically determined. The washing step with DMAc was essential to prevent already dissolved cellulose from precipitating in water.

The dissolved cellulose samples were analyzed by HPSEC on a Dionex ICS-1100 system using a $20 \mu \mathrm{m}$ guard $(50 \times 7.5 \mathrm{~mm})$ and 4 PL gel $20 \mu \mathrm{m}$ Mixed-A $(300 \times 7.5 \mathrm{~mm})$ columns. Samples were eluted with DMAc containing $0.9 \% \mathrm{LiCl}$ at $30{ }^{\circ} \mathrm{C}$ and $1 \mathrm{~mL} / \mathrm{min}$. Weight and number average molecular weights ( $\mathrm{Mw}, \mathrm{Mn})$ were determined with Thermo Scientific $^{\mathrm{TM}}$ Chromeleon ${ }^{\mathrm{TM}} 7.2$ software (extension pack GPC templates). Polydispersity was calculated as the quotient of weight and number average molecular weight (Mw/Mn). Calibration was done with pullulan standards (PSS Polymer Standard Services, Mainz, Germany; Fluka/Sigma Aldrich, St. Louis, USA) with the following molar masses at the peak maximum (Mp): 2,560,000 Da, 708,000 Da, 337,000 Da, 194,000 Da, 107,000 Da, 47,100 Da, 21,100 Da, $9600 \mathrm{Da}, 6100 \mathrm{Da}, 1080 \mathrm{Da}$, and $342 \mathrm{Da}$.

\section{RESULTS AND DISCUSSION}

\section{Optimization of Dissolution Time and Temperature of Wheat Straw Samples in DMAC/LiCl}

Wheat straw treated at mild AEO conditions $\left(160{ }^{\circ} \mathrm{C}, 30 \mathrm{~min} ., 60 \mathrm{wt} . \% \mathrm{EtOH}\right)$ was selected for optimization of dissolution parameters because it was the most difficult to dissolve in $\mathrm{DMAc} / \mathrm{LiCl}(9 \%)$, the most common cellulose solvent. In a preliminary experiment, treated wheat straw samples were dissolved at $32{ }^{\circ} \mathrm{C}, 54{ }^{\circ} \mathrm{C}$, and $80{ }^{\circ} \mathrm{C}$ for up to $72 \mathrm{~h}$ in $\mathrm{DMAc} / \mathrm{LiCl}(9 \%)$, and the obtained molecular weight distributions are shown in Fig. 2.

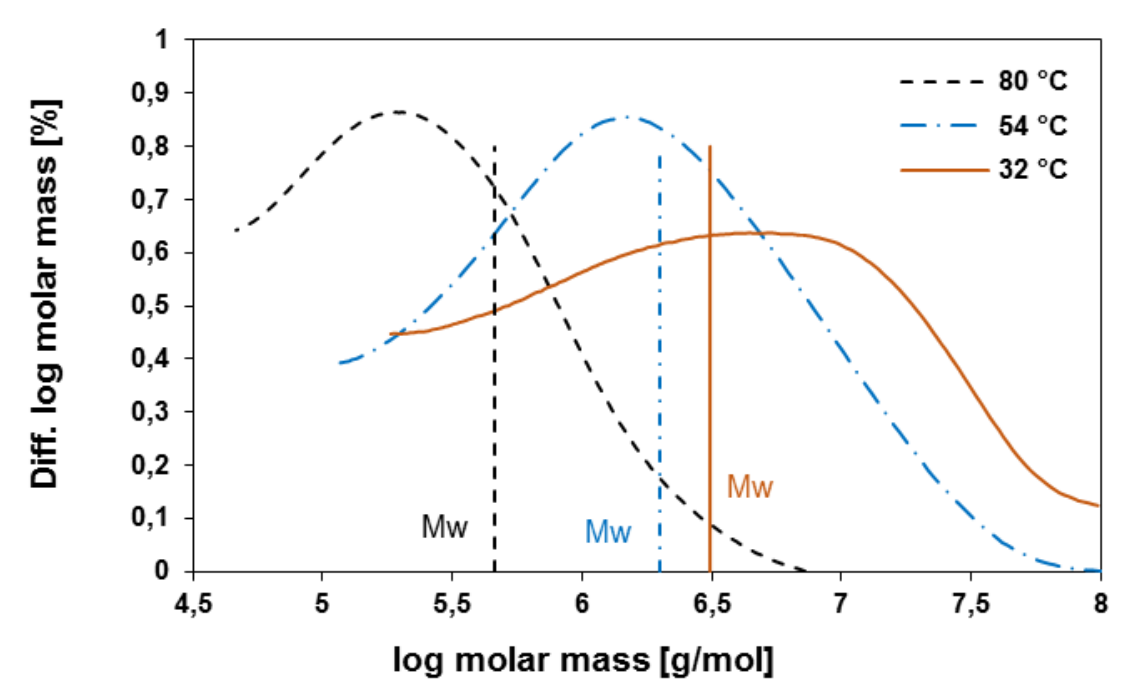

Fig. 2. Molecular weight distributions of LHW and AEO-treated wheat straw samples (mild AEO treatment: $160{ }^{\circ} \mathrm{C}, 30$ min., 60 wt. $\% \mathrm{EtOH}$ ) at $32^{\circ} \mathrm{C}, 54^{\circ} \mathrm{C}$, and $80^{\circ} \mathrm{C}$ dissolved in DMAc/LiCl $(9 \%)$ for $72 \mathrm{~h} . M_{\mathrm{w}}$ : Weight average molecular weight 
A distinct decrease in molecular weight and degree of polymerization occurred at $80{ }^{\circ} \mathrm{C}$ (DP: $~ 3000$ ) compared with $54{ }^{\circ} \mathrm{C}$ (DP: 12,000 ) and $32{ }^{\circ} \mathrm{C}$ (DP: 19,000), confirming severe degradation at elevated temperatures even below $85{ }^{\circ} \mathrm{C}$, as shown by Potthast et al. (2002). The effect was ascribed to the cleavage of the glycosidic bonds through an electrophilic attack of a keteniminium cation formed from DMAc, resulting in low molecular weights (Rosenau et al. 2006). Consequently, further variations of dissolution time between $12 \mathrm{~h}$ to $72 \mathrm{~h}$ were carried out at $32{ }^{\circ} \mathrm{C}$ and $54{ }^{\circ} \mathrm{C}$ only.

The degree of polymerization and amount of sample in solution were determined for each setting and are shown in Fig. 3. The highest degree of polymerization $(\sim 19,000)$ was obtained at $32{ }^{\circ} \mathrm{C}$ with steadily increasing molecular weight over time, while $54{ }^{\circ} \mathrm{C}$ resulted in a greater variation with a tendency to lower degrees of polymerization over time $(\sim 14,000)$. It is plausible that longer cellulose chains in the crystalline parts of the fiber require more time to dissolve than shorter chains in less-ordered regions (Henniges et al. 2011). The lower degrees of polymerization at $54{ }^{\circ} \mathrm{C}$ therefore indicate degradation of cellulose, leading to shorter chains, which is consistent with the corresponding higher amount of sample found in solution. Even at a higher amount of sample in solution $(61.3 \%$ after $72 \mathrm{~h}$ at $32{ }^{\circ} \mathrm{C}$ compared with $58.6 \%$ after $12 \mathrm{~h}$ at $54{ }^{\circ} \mathrm{C}$ ), degree of polymerization was remarkably higher at $32{ }^{\circ} \mathrm{C}$ than at $54{ }^{\circ} \mathrm{C}$. The $32{ }^{\circ} \mathrm{C}$ dissolution temperature and $72 \mathrm{~h}$ dissolution time were the most suitable for determining molecular weights of LHW and AEO treated wheat straw samples with minimal cellulose chain length alteration by degradation during dissolution.

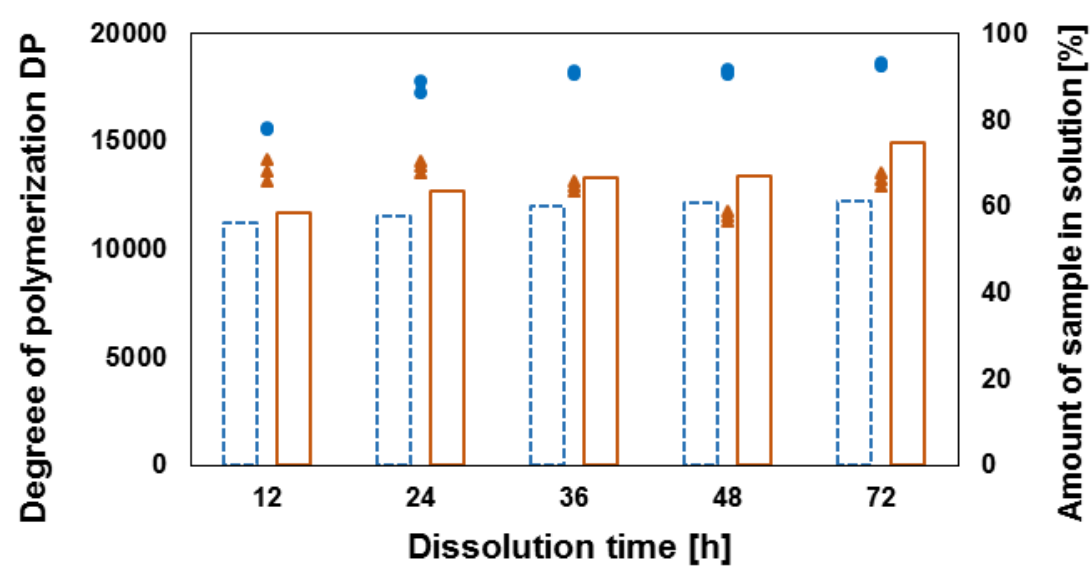

¿'Amount of sample in solution (a), and $\square$ Amount of sample in solution (b), and

- degree of polymerization at $32^{\circ} \mathrm{C} \quad \Delta$ degree of polymerization at $54{ }^{\circ} \mathrm{C}$

Fig. 3. Degree of polymerization and amount of dissolved sample of LHW and AEO treated wheat straw samples (mild AEO treatment: $160^{\circ} \mathrm{C}, 30$ min., 60 wt. $\%$ EtOH) at $32{ }^{\circ} \mathrm{C}$ and $54{ }^{\circ} \mathrm{C}$ dissolved in DMAc / $\mathrm{LiCl}(9 \%)$ for $12 \mathrm{~h}$ to $72 \mathrm{~h}$. Duplicate measurements and their mean are displayed.

\section{Cellulose Degradation of Wheat Straw during LHW and AEO Treatment with Varying Amounts of Ethanol}

The DP of cellulose in wheat straw fibers determined after LHW and AEO treatment ranged between 6,400 and 18,000 while varying ethanol-to-water ratios between $20 \%$ and $90 \%$, respectively (Table 1 ). 
Table 1. Degree of Polymerization (DP) and Polydispersity of Wheat Straw Samples after LHW and AEO Treatment with 20\%,60\%, and $90 \%$ Ethanol-toWater Ratio of Two Different Batches (a) and (b)

\begin{tabular}{|c|c|c|c|c|}
\hline $\begin{array}{c}\text { Ethanol-to- } \\
\text { water ratio (\%) }\end{array}$ & DP (a) & Polydispersity (a) & DP (b) & Polydispersity (b) \\
\hline 20 & 6400 & 6.9 & 8800 & 7,9 \\
\hline 60 & 14000 & 6.2 & 17000 & 5.1 \\
\hline 90 & 18000 & 5.0 & 18000 & 4.1 \\
\hline
\end{tabular}

The determined DPs and associated amounts of dissolved sample in DMAc/LiCl are shown in Fig. 4.

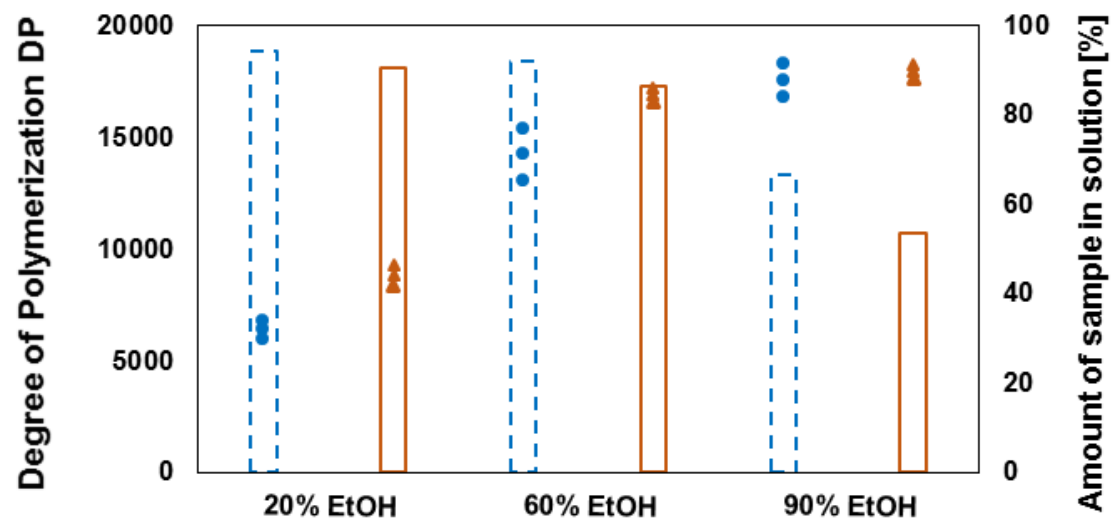

$\llcorner$ Amount of sample in solution (a), and $\square$ Amount of sample in solution (b), and

- degree of polymerization at $32{ }^{\circ} \mathrm{C} \quad \Delta$ degree of polymerization at $32{ }^{\circ} \mathrm{C}$

Fig. 4. Degree of polymerization and amount of dissolved sample of LHW and AEO treated wheat straw samples (AEO treatment: $200{ }^{\circ} \mathrm{C}, 30 \mathrm{~min}$.) at an ethanol-to-water ratio of $20 \%, 60 \%$, and $90 \%$ of two different wheat straw batches (a) and (b). Duplicate measurements and their mean are displayed for each batch.

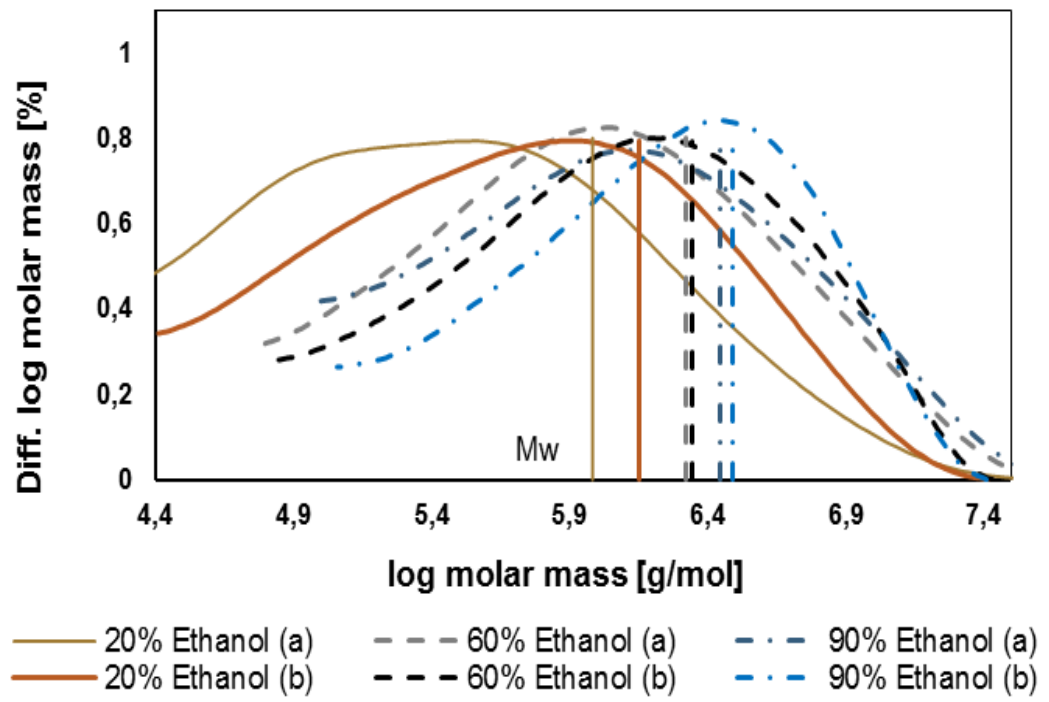

Fig. 5. Molecular weight distribution of wheat straw cellulose after LHW and AEO treatment at an ethanol-to-water ratio of $20 \%, 60 \%$, and $90 \%$ of two different wheat straw batches (a) and (b). $M_{\mathrm{w}}$ is weight average molecular weight. 
In both analyzed batches, lower ethanol-to-water ratio resulted in lower cellulose DPs and higher amounts of sample in solution. As shown in Fig. 5, MWDs of wheat straw cellulose after treatment with $20 \%, 60 \%$, and 90 wt.\% ethanol, despite a shift to lower MWs and DP, also revealed an increase in polydispersity with decreasing ethanol content, indicating cellulose depolymerization resulting in a broadened MWD in both batches.

The chemical composition of the fibers was also examined. Depending on the parameter settings, the fibers contained $36.3 \%$ to $54.2 \%$ glucan, $3.5 \%$ to $17.9 \%$ xylan, $0 \%$ to $0.7 \%$ arabinan, $0 \%$ to $0.6 \%$ galactan, $0 \%$ to $0.8 \%$ mannan, $0.7 \%$ to $3.6 \%$ ash, $8 \%$ to $16 \%$ lignin, and $2.5 \%$ to $14.3 \%$ extractives, as shown in Fig. 6. At an ethanol-to-water ratio of $20 \%$, most of the xylan was removed, and the amount recovered by extraction increased by a factor of 3 to 4 in comparison to $60 \%, 90 \%$, and the untreated wheat straw.

Delignification increased in comparison with $90 \%$ ethanol and the untreated wheat straw, but it remained at a similar level with the $60 \%$ ethanol. The more effective removal of xylan was probably due to its better solubility in solvents with a higher percentage of water. By dissolving most of the xylan during AEO treatment at $20 \%$ ethanol, acetyl groups attached to wheat straw xylan were also cleaved, resulting in a dilute acidic solution (Denner 2016, unpublished data). This may have promoted hydrolysis and degradation reactions as indicated by the relatively low DP and broad MWD of cellulose at $20 \%$ ethanol. Effective xylan removal led to a better accessibility of the solvent, which may also have contributed to the observed degradation of the wheat straw cellulose.

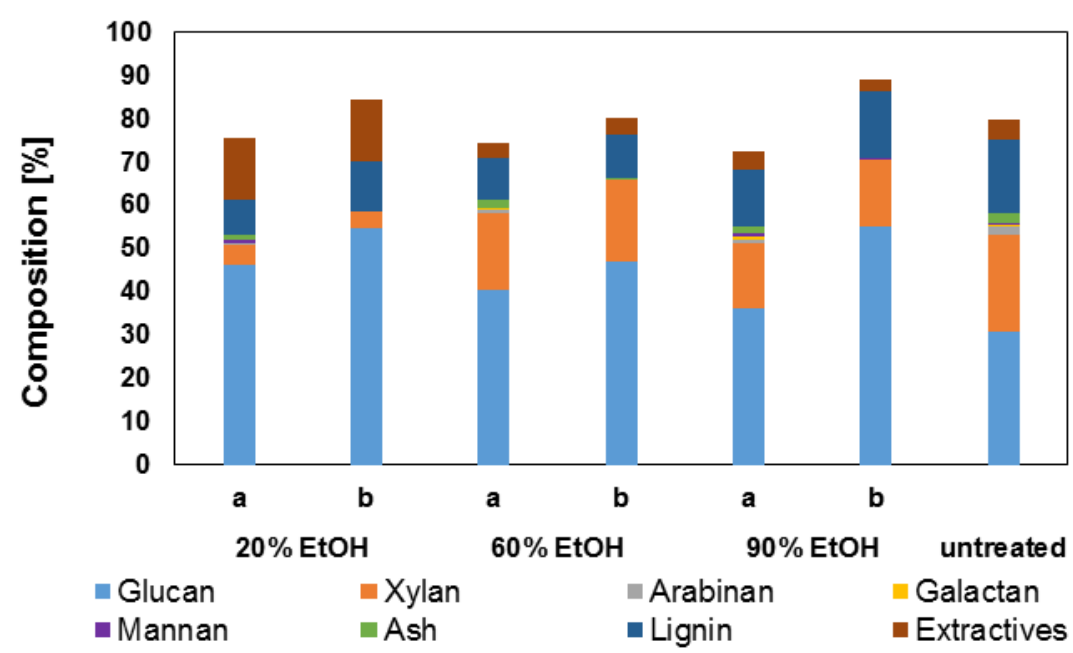

Fig. 6. Chemical composition of wheat straw treated by LHW and AEO at an ethanol-to-water ratio of $20 \%, 60 \%$, and $90 \%$ of two different wheat straw batches (a) and (b) and an untreated reference sample

The unusually high percentage of extractives at $20 \%$ ethanol may have resulted from condensation of lignin with carbohydrates and/or carbohydrate degradation products such as furfural from xylan, resulting in compounds known as "pseudo lignin" (Aoyama et al. 1995; Carvalheiro et al. 2009). Such condensation products may first dissolve in the hot extraction solvent, followed by precipitation on the fibers upon cooling, and re-dissolution during extraction with acetone $/ \mathrm{H}_{2} \mathrm{O}(95 / 5)$. However, "pseudo lignin" has also been reported to result in increased Klason lignin contents during dilute acid pretreatment of lignocellulosic biomass (Foston and Ragauskas 2010; Sannigrahi et al. 2011). Though 
Klason lignin did not increase during AEO treatment at an ethanol-to-water ratio of $20 \%$, the amount of extractives did increase remarkably. It is likely that most of the putative "pseudo lignin" was extracted during acetone $/ \mathrm{H}_{2} \mathrm{O}(95 / 5 \mathrm{vol} \%)$ extraction, and thus did not significantly affect the Klason lignin.

In Fig. 7, the UV and RI signals of HPSEC of the wheat straws treated with 20\%, $60 \%$, and 90 wt.\% ethanol are compared. Although cellulose and xylan have no UV absorbance, UV and RI signals co-eluted, suggesting lignin-carbohydrate linkages. This conclusion was supported by the observation that free lignin obtained from the pulping liquor eluted at higher retention times ( $\sim 36 \mathrm{~min}$, not shown), corresponding to noticeably lower MW $(\log$ MW 1.5) than that of cellulose or xylan.

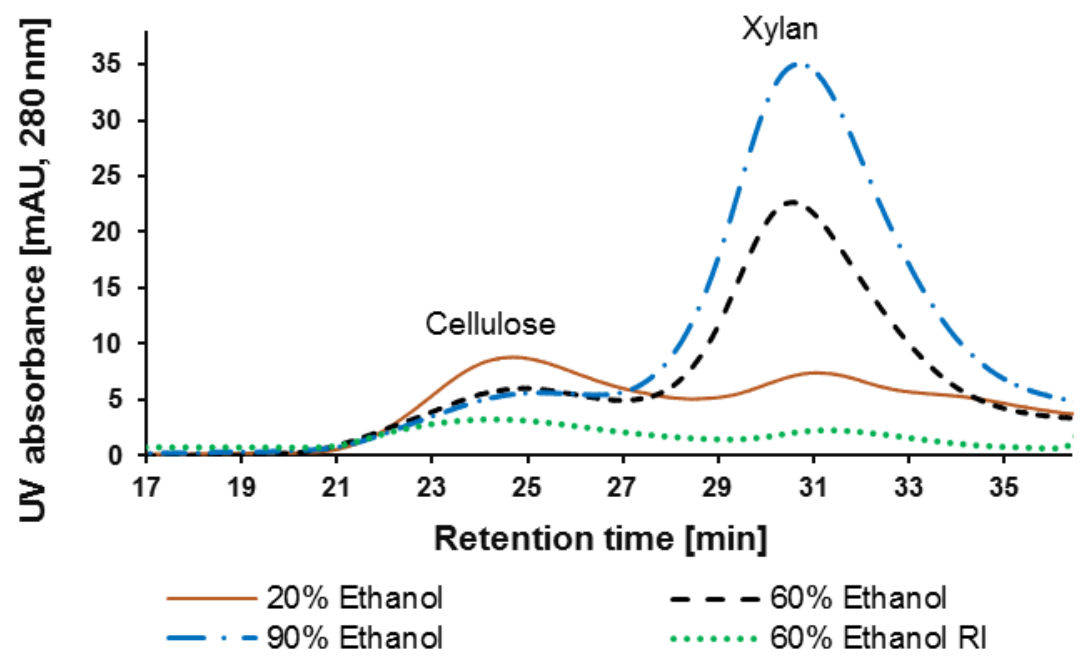

Fig. 7. HPSEC (UV at $280 \mathrm{~nm}$ ) of wheat straw lignin-carbohydrate complexes after AEO treatment at an ethanol-to-water ratio of $20 \%, 60 \%$, and $90 \%$. For comparison, the RI signal is also shown for $60 \%$ ethanol.

Wet chemical data further showed that the amount of residual lignin and xylan simultaneously decreased with lower ethanol-to-water ratios. This finding is in good agreement with the UV elution profiles in Fig. 2, showing a distinct decrease in absorption at the retention time of xylan. Similar results were found by Hutterer et al. (2016), reporting a tight association of residual lignins and low MW xylans in alkaline lye after alkaline extraction of hardwood. Moreover, some UV absorbance co-eluting with cellulose $\left(M_{\mathrm{p}}\right.$ $24.3 \mathrm{~min}$.) was also detected, suggesting that a few linkages may also exist between lignin and cellulose.

Future research is needed to support the hypothesis that the high amount of extractives, occuring during AEO treatment at low ethanol-to-water ratio, could result from condensation of lignin with carbohydrates and/or carbohydrate degradation products (pseudo lignin). In general, the data provided here may be useful for further development of AEO treatment processes for wheat straw. 


\section{CONCLUSIONS}

1. The established dissolution method was suitable for relative comparisons of molecular weight distributions of differently treated wheat straw fibers and hence for obtaining information regarding the severity of combined liquid hot water (LHW) and aqueous ethanol organosolv (AEO) treatments in terms of cellulose degradation.

2. Overall, AEO treatment at a low ethanol-to-water ratio favours efficient removal of xylan from wheat straw, but at the price of a greatly reduced fiber quality in terms of degree of polymerization. Ultraviolet (UV) detection after high performance sizeexclusion chromatography (HPSEC) suggested a tight association of residual lignin and xylan, as well as few linkages that may also exist between lignin and cellulose.

\section{ACKNOWLEDGMENTS}

The authors are grateful to Prof. Antje Potthast for technical advice and providing cellulose reference samples. The authors also thank Dr. Felix Weinwurm and Jürgen Denner for providing the LHW and AEO treated wheat straw samples.

\section{REFERENCES CITED}

Aoyama, M., Seki, K., and Saito, N. (1995). "Solubilization of bamboo grass xylan by steaming treatment," Holzforschung 49(3), 193-196. DOI:

10.1515/hfsg.1995.49.3.193

Bilalis, D., Sidiras, N., Economou, G., and Vakali, C. (2003). "Effect of different levels of wheat straw soil surface coverage on weed flora in Vicia faba crop," J. Agron. Crop Sci. 189(4), 233-241. DOI: 10.1046/j.1439-037X.2003.00029.x

Carvalheiro, F., Silva-Fernandes, T., Duarte, L. C., and Gírio, F. M. (2009). "Wheat straw autohydrolysis: Process optimization and products characterization," Appl. Biochem. Biotech. 153(1-3), 84-93. DOI: 10.1007/s12010-008-8448-0

Chen, H. (2014). "Chemical composition and structure of natural lignocellulose," in: Biotechnology of Lignocellulose: Theory and Practice, Springer Netherlands, Dordrecht, Netherlands, pp. 25-71. DOI: 10.1007/978-94-007-6898-7_2

Davis, M. W. (1998). "A rapid modified method for compositional carbohydrate analysis of lignocellulosics by high $\mathrm{pH}$ anion-exchange chromatography with pulsed amperometric detection (HPAEC/PAD)," J. Wood Chem. Technol. 18(2), 235-252. DOI: $10.1080 / 02773819809349579$

Dawsey, T., and McCormick, C. L. (1990). "The lithium chloride/dimethylacetamide solvent for cellulose: A literature review," J. Macromol. Sci. Rev. Macromol. Chem. Phys. 30(3-4), 405-440. DOI: 10.1080/07366579008050914

Denner, J. (2016). Investigation of the Lignin- and Carbohydrate-Extraction Kinetics during Organosolv Treatment of Wheat Straw, Master's Thesis, Technical University Vienna, Austria.

DIN ISO 3696 (1991). "Water for analytical laboratory use; Specification and test methods," DIN Standards Committee Materials Testing, Berlin, Germany. 
Du, X., Gellerstedt, G., and Li, J. (2013). "Universal fractionation of lignin-carbohydrate complexes (LCCs) from lignocellulosic biomass: An example using spruce wood," Plant J. 74(2), 328-338. DOI: 10.1111/tpj.12124

Foston, M., and Ragauskas, A. J. (2010). "Changes in lignocellulosic supramolecular and ultrastructure during dilute acid pretreatment of Populus and switchgrass," Biomass Bioenerg. 34(12), 1885-1895. DOI: 10.1016/j.biombioe.2010.07.023

Heinze, T., and Koschella, A. (2005). "Solvents applied in the field of cellulose chemistry: A mini review," Polímeros 15(2), 84-90. DOI: 10.1590/S010414282005000200005

Henniges, U., Kostic, M., Borgards, A., Rosenau, T., and Potthast, A. (2011). "Dissolution behavior of different celluloses," Biomacromolecules 12(4), 871-879. DOI: $10.1021 / \mathrm{bm} 101555 \mathrm{q}$

Henniges, U., Vejdovszky, P., Siller, M., Jeong, M.-J., Rosenau, T., and Potthast, A. (2014). "Finally dissolved! Activation procedures to dissolve cellulose in DMAc/LiCl prior to size exclusion chromatography analysis-A review," Current Chromatography 1(1), 52-68. DOI: 10.2174/2213240601666131118220030

Huijgen, W., Smit, A., De Wild, P., and Den Uil, H. (2012). "Fractionation of wheat straw by prehydrolysis, organosolv delignification, and enzymatic hydrolysis for production of sugars and lignin," Bioresource Technol. 114, 389-398. DOI: 10.1016/j.biortech.2012.02.143

Hutterer, C., Schild, G., Kliba, G., and Potthast, A. (2016). "Lignin profiling in extracted xylans by size-exclusion chromatography," Carbohyd. Polym. DOI:

10.1016/j.carbpol.2016.06.019

Ishii, D., Tatsumi, D., and Matsumoto, T. (2008). "Effect of solvent exchange on the supramolecular structure, the molecular mobility and the dissolution behavior of cellulose in LiCl/DMAc," Carbohyd. Res. 343(5), 919-928. DOI: 10.1016/j.carres.2008.01.035

Kabel, M. A., Bos, G., Zeevalking, J., Voragen, A. G., and Schols, H. A. (2007). "Effect of pretreatment severity on xylan solubility and enzymatic breakdown of the remaining cellulose from wheat straw," Bioresource Technol. 98(10), 2034-2042. DOI: 10.1016/j.biortech.2006.08.006

Kamm, B., and Kamm, M. (2004). "Principles of biorefineries," Appl. Microbiol. Biot. 64(2), 137-145. DOI: 10.1007/s00253-003-1537-7

Kamm, B., Kamm, M., Schmidt, M., Starke, I., and Kleinpeter, E. (2006). "Chemical and biochemical generation of carbohydrates from lignocellulose-feedstock (Lupinus nootkatensis)—Quantification of glucose," Chemosphere 62(1), 97-105. DOI: 10.1016/j.chemosphere.2005.03.073

Kim, Y., Hendrickson, R., Mosier, N. S., and Ladisch, M. R. (2009). "Liquid hot water pretreatment of cellulosic biomass," in: Biofuels: Methods and Protocols, pp. 93-102. DOI: 10.1007/978-1-60761-214-8_7

Klemm, D., Bertram, P., and Heinze, T. (1998). Comprehensive Cellulose Chemistry: Fundamental and Analytical Methods, Wiley, Hoboken, NJ, USA. DOI: $10.1002 / 3527601929$

Lawoko, M. (2005). Lignin Polysaccharide Networks in Softwood and Chemical Pulps: Characterisation, Structure and Reactivity, Doctoral Thesis, KTH Royal Institute of Technology, Stockholm, Sweden. 
Liebert, T. (2010). "Cellulose solvents-remarkable history, bright future," in: Cellulose Solvents: For Analysis, Shaping and Chemical Modification, ACS Publications, Washington, D.C., USA, pp. 3-54. DOI: 10.1021/bk-2010-1033.ch001

Lindemann, M. (2016). Cellulose Depolymerization during Organosolv Treatment, Master Thesis, Technische Universität Wien, Wien, Austria.

Montane, D., Farriol, X., Salvado, J., Jollez, P., and Chornet, E. (1998). "Application of steam explosion to the fractionation and rapid vapor-phase alkaline pulping of wheat straw," Biomass and Bioenerg. 14(3), 261-276. DOI: 10.1016/S0961-9534(97)100459

Nabarlatz, D., Ebringerová, A., and Montané, D. (2007). "Autohydrolysis of agricultural by-products for the production of xylo-oligosaccharides," Carbohyd. Poly. 69(1), 2028. DOI: 10.1016/j.carbpol.2006.08.020

Nehls, I., Wagenknecht, W., and Philipp, B. (1995). "13C-NMR spectroscopic studies of cellulose in various solvent systems," Cell. Chem. Technol. 29(3), 243-251

Potthast, A., Rosenau, T., Sixta, H., and Kosma, P. (2002). "Degradation of cellulosic materials by heating in DMAc/LiCl," Tetrahedron Lett. 43(43), 7757-7759. DOI: 10.1016/S0040-4039(02)01767-7

Rosenau, T., Potthast, A., and Kosma, P. (2006). "Trapping of reactive intermediates to study reaction mechanisms in cellulose chemistry," in: Polysaccharides II, Springer Science \& Business Media, Berlin/Heidelberg, Germany pp. 153-197. DOI: 10.1007/12_098

Ruiz, H. A., Ruzene, D. S., Silva, D. P., da Silva, F. F. M., Vicente, A. A., and Teixeira, J. A. (2011). "Development and characterization of an environmentally friendly process sequence (autohydrolysis and organosolv) for wheat straw delignification," Appl. Biochem. Biotech. 164(5), 629-641. DOI: 10.1007/s12010-011-9163-9

Saha, B. C., and Cotta, M. A. (2006). "Ethanol production from alkaline peroxide pretreated enzymatically saccharified wheat straw," Biotechnol. Progr. 22(2), 449453. DOI: $10.1021 / \mathrm{bp} 050310 \mathrm{r}$

Sannigrahi, P., Kim, D. H., Jung, S., and Ragauskas, A. (2011). "Pseudo-lignin and pretreatment chemistry," Energ. Environ. Sci. 4(4), 1306-1310. DOI: 10.1039/C0EE00378F

Silva, A. A., and Laver, M. L. (1997). "Molecular weight characterization of wood pulp cellulose: Dissolution and size exclusion chromatographic analysis," Tappi J. 80(6), $173-180$

Sjöholm, E., Gustafsson, K., Eriksson, B., Brown, W., and Colmsjö, A. (2000). "Aggregation of cellulose in lithium chloride/N, N-dimethylacetamide," Carbohyd. Polym. 41(2), 153-161. DOI: 10.1016/S0144-8617(99)00080-6

Striegel, A. (1997). "Theory and applications of DMAc/LiCl in the analysis of polysaccharides," Carbohydrate Polymers 34(4), 267-274. DOI: 10.1016/S01448617(97)00101-X

TAPPI T222 om-98 (1998). "Acid-insoluble lignin in wood and pulp," TAPPI Press, Atlanta, GA.

TAPPI T211 om-02 (2002). "Ash in wood, pulp, paper and paperboard: Combustion at $525{ }^{\circ} \mathrm{C}$," TAPPI Press, Atlanta, GA.

TAPPI T204 cm-07 (2007). "Solvent extractives of wood and pulp," TAPPI Press, Atlanta, GA.

TAPPI UM 250 (1991). "Acid-soluble lignin in wood and pulp," TAPPI Press, Atlanta, GA. 
Ward, P., Wohlt, J., Zajac, P., and Cooper, K. (2000). "Chemical and physical properties of processed newspaper compared to wheat straw and wood shavings as animal bedding1," J. Dairy Sci. 83(2), 359-367. DOI: 10.3168/jds.S0022-0302(00)74887-9

Weinwurm, F., Cunha, J., and Friedl, A. (2012). "Pretreatment of wheat straw by liquid hot water and organosolv processes," Chemical Engineering Transactions 29, 541546. DOI: 10.3303/CET1229091

Weinwurm, F., Denner, J., Turk, T., and Friedl, A. (2016). "Valorising of wheat straw by applying combined liquid hot water and ethanol organosolv pretreatment," in: 19th International Conference on Process Integration, Modeling and Optimization for Energy Savings and Pollution Reduction, Aidic Servizi Srl, Milan, Italy, pp. 373-378.

Wildschut, J., Smit, A. T., Reith, J. H., and Huijgen, W. J. (2013). "Ethanol-based organosolv fractionation of wheat straw for the production of lignin and enzymatically digestible cellulose," Bioresource Technol. 135, 58-66. DOI: 10.1016/j.biortech.2012.10.050

Young, R. A., and Akhtar, M. (1998). Environmentally Friendly Technologies for the Pulp and Paper Industry, Wiley, Hoboken, NJ, USA.

Zhao, X., Li, S., Wu, R., and Liu, D. (2017). "Organosolv fractionating pre-treatment of lignocellulosic biomass for efficient enzymatic saccharification: Chemistry, kinetics, and substrate structures," Biofuels, Bioprod. Bior. DOI: 10.1002/bbb.1768

Article submitted: June 30, 2017; Peer review completed: August 19, 2017; Revised version received: October 18, 2017; Accepted: October 23, 2017; Published: October 30, 2017.

DOI: 10.15376/biores.12.4.9407-9419 